\title{
AMSTERDAMSCHE FORENSEN IN DE ZEVENTIENDE EEUW.
}

Het aanhangige wetsontwerp tot herziening der algemeene regelen ten aanzien der plaatselijke belastingen heeft de forensen$k$ westie weder aan de orde gesteld.

Zooals men weet, bepaalt het ontwerp daaromtrent in art.

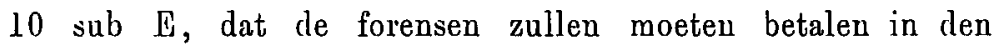
hoofdelijken omslag der gemeente waar zij niet wonen, Inaar wel hun bedrijf uitoefenen, voor vier twaalfde gedeelten van den aanslag over een vol jaar.

In de vrij sobere Memorie vau Toelichting wordt hieromtrent alleen opgemerkt: $1^{\circ}$ dat evenzeer als iemand bij twee gemeenteu belastingschuldig wordt, wanneer hij een goed gedeelte des jaars in eene gemeente buiten zijn hoofdverblijf verblijft, - dit ook het geval behoort te zijn, wanneer hij in eene gemeente buiten zijn hoofdverblijf een kantoor of andere inrichting voor het uitoefenen van eenig bedrijf heeft en te dien einde die gemeente veelvuldig en regelmatig bezoekt.

En $2^{\circ}$ dat het $n$ iet de bedoeling is de bijdrage voor 4 maanden te vragen van hen die geregeld, al is het nog zoo dikwijls, eene plats bezoeken zonder er eenig gebouwd eigendom of deel daarvan in gebruik of medegebruik te hebben. In beursbelasting, markt- of staangelden, havengelden, kunnen de zoodanigen tot eene bijdrage volyens art. $240 \mathrm{f}$ der Gemeentewet verplicht worden.

Dit klinkt mild, maar uit de redactie van art. 10 E. 4,0 blijkt dat de wet dit "medegebruik" zeer ruim opvat en daaronder brengt ieder die tot uitoefening van een bedrijf gedurende meer dan 90 dagen aanwezig is in een kantoor, winkel, werkplaats of andere vaste inrichting of tot vervulling eener dienstbetrekking. Derhalve zullen kleine beambten, kantoor- en winkelbedienden, ambachtslieden en zelfs arbeiders dikwijls in twee gemeenten moeten betalen. Dit kan onbillijk werken, daar juist voor deze personen niet zelden op een be- 
paalde plaats moeilijk geschikte woningen zijn te bekomen en ook voor hen gegronde redenen, bijv. van gezondheid, kunuen bestaan, die tot het toch reeds kostbare uitwonen nopen. Stel een Amsterdamsch kantoorbediende moet voor zijne kinderen in andere lucht, bijv. Bussum, gaan wonen. Is dit het oogenblik om hem eene extra-belasting op te leggen? Tal van gemeenten zijn er waar dagelijks vele personen van elders hun werk komen verrichten, niet uit willekeur, maar oundat het moeilijk anders kan. Bin hun inutal zal nog grooter worden, wanneer de verkeersmiddelen worden anngevuld, de woningtoestanden verbeterd en meu, eveuals in het buitenland, de arbeiders op eenigen afstand ruimere woningen en een stakje grond verschaft. Feen enkel algemeen belang wordt gebaat door samenhokking binuen de gemeente waar men werkt. Wellicht zal men beweren dat zulke kleine belastingschuldigen niet zullen worden aangeslagen. Maar daarin zou men zich vergissen. Vele gemeenten beginnen reeds bij inkomens van f 4,00 aan te slaan en men zal vreeınden allerminst sparen. Het gemis van indirecte belastingeu dwingt onze besturen laag te beginnen.

Het komt mij daarom eenigszins twijfelachtig voor of met deze bepalingen de forensen-kwestie naar billijkheid zal zijn opgelost. Men had zich moeten bepalen tot de meer vermogende uitwonenden, waarom het toch wel te doen zal zijn, nl. de hoofden van het bedrijf en huu gemachtigden, maar de ondergeschikte personen vrijlaten. Overigens mogen de forensen dankbaar wezen als zij er met vier maanden belasting afkomen. De wind waait tegenwoordig uit een hoek die gunstig is voor de groote steden en minder gunstig voor het platteland. Daar de aanslag louter op eene fictie berust, had men in het stelsel der wet even goed 6,9 of zelfs 12 maanden betaalplicht voor den zoogenaamden belastingschuldige kunnen anuemen. Het is eenvoudig eene vraag van discretie, want de forens komt en gaat in den regel het geheele jaar door. Anders is het wanneer iemand bijv. eenige uaanden achtereen op zijn buitenverblijf vertoeft. Het is dan niet twijfelachtig dat hij beurtelings in twee gemeenten woout en evenmin over hoeveel maanden hij in ieder van beide behoort te betalen.

Oppervlakkig zou men meenen dat de forensen-kwestie ding- 
teekent van den jongsten tijd, oudat zij in nauw verband staat met den aanleg vau verschillende spoorwegen eu de min duidelijke redactie van sommige artikeleu onzer betrekkelijk nieuwe Gemeentewet. Doch hierin zou men zich bedriegen. Er schijnt inderdaad niets nieuws onder de zon en ook hier geldt liet "schon dagewesen".

De vraag hoever men kan gaan met het belasten van uitwonenden heeft ook in vroegere eeuwen den wetgever veel last en hoofdbreken bezorgd.

Vooral geldt dit een gewest als Holland, eene stad als Amsterdam, waar de gemeene lasten meestal hoog waren en de handeldrijvende bevolking, ten deele uit vreemdelingen bestaande, aan velerlei wisseling is blootgesteld.

Natuurlijk zag men ook toen min of meer vermogende personen ongaarne vertrekken en trachtte hen, ook na hun vertrek, door allerlei middelen in de belastingen te doen bijdragen.

Zoo beklaagt zich in het hier volgende request een gewezen Amsterdamsch koopman, die om geheel particuliere redenen naar Antwerpen was verhuisd, over de toepassing van het Placcaat van Holland van 3 April 1677. Het valt niet te ontkenuen dat dit staatstuk inderdaad zeer inhalige maatregelen nam.

Uit dit request blijkt ook hoe men onder den patricischen regeeringsvorm op vertrouwelijker toon tot de overheid sprak dan thans.

Het placaet van de E. Heeren Staten vau Hollant eude Westvrieslandt heb ick gecomuniceert aen verscheijde van mijne Vrienden. Welcke eenpaerichlijck Sustineeren en absolutelijck houden dat mij niet can raeken als sijude buijten haer $\mathbf{E}$. Jurisdictie, de selve niet verder streckende als op de geenen die sich hebben geretireert in andere van hun E. Provintien daerine minder belast wert, off wel in andere plaetsen alwaer Sustineeren geëxcuseert te sijn, En om te ontgaen den twee honderste penningh van de Provintie van Hollandt off West Vrieslandt:

Mijn Opinie is dat de geene die sich hebben geritireert onder de Dominatie van den Coningh van Spagnien gants geexempteert sijn van 't selve placcaet, aengesien men op twee plaetsen personeelijck niet en can betaelen tot de contributie van den Oorlogh inde welcke Spagnien en Hollaudt eeneu selfden intherest hebben. En ick contribuere alhier in alle lasten, en volgens 't geene getaxeert ben; En hebbe mij niet 
geritireert uijt Hollandt ten aensien vaude twee honderste penningh, maer om diverse particuliere consideratien, alsoo al voor lange jaere inclinatie gehadt hebbe om te comeu alhier bij mijn maechschap, en Vrienden wonen, Sijnde hier in Antwerpen twee mael getrout. Ick ben tot Austerdam comen wonen uijt mijn vrije wille sonder gecontracteert te hebben met de Heeren Staten off inet de Heeren Magistraten van Amsterdam hoe langen tijdt ick soude wonen, en sijnde een vrij landt soo can men cowen en uijtgaen wanneer men 't geraeden vint, terwijl der geen contrarij placaten en siju en wie isser die sich soude stabileeren in een plaetse van waer men sich niet soude connen retireeren als men wilde?

In 't jaer 1658 isser gemaeckt een tractaet van issue tussen Ansterdam en Antwerpen, sonder datt ijets van wedersijden wert betaelt, 't welck te kennen geeft dat men sich can retireeren sonder aen eenige coutributie onderworpen te sijn als of men sich retireerde in audere provintien onder de Jurisdictie van de Heeren Staten General, gelijck Uijtrecht, Gelderlandt, Overijssel en Ommelanden alwaer wijnich wert betaelt ten respecte der Provintie van Hollandt: ${ }^{1}$ ) En u/smede voor de gecme die sich geretireert heblew bin cleigne sheden, dorpen. en hofstedlen omtrent Amsterlam, alwaer noch daegelijoks comen hinn. affiaires verrichten, Ende door desen midldel te ontgaen de twee honderste penningh en grote onconsten tie daar worlen gecontribueert tot ondlerhout van 't landt, of wel selfs voor de geene die sich geretireert hebben in Vlaanderen en Brabandt in de steden toebehoorende de E. Heeren Staten General als, Hulst, Breda, 's-Hertogenbosch, Bergen op Zoom \&z maer niet op de Steden die onder de dominatie sijn vanden Coningh van Spagnien, eu dat can oock niet verder strecken als op de landen, huijsen, en immeubelen maer niet op de Conpmanschappen. Terwijl d'eene Overicheijt geen macht of Jurisdictie heeft over d'onderdaenen van eenen anderen Heer ofte Prince die independent is, ende vervolgens over des selfs nnderdaenen, persoonen en goederen niet verder conneu statueeren als voor sooveele de selve goederen in haer territoir soude vast gesitneert sijn, sonder over meubele goederen ofte Coopmauschappen van sodanige haere subjetten niet sijnde, te connen disponeeren terwijl daermede de vrije Commercie soude geturbeert wesen, tegens 't gemeene recht der Volckeren - - -

Ende alsoo de Magistrat deser Stede Antwerpen mij Privilegien hebben verleent eer ick alhier ben gecomen, als oock van geleijcken den Gouveneur deser landen, soo sullen sij

1) De cursiveering der volgende regels is door mij geschied.

A. D. จ. A. DE C.

Econ. 1897. 
g'obligeert sijn mij te protegeeren ingevalle d'E. Heeren Staten soude pretendeeren mij te willen molesteeren in mijn persoon off goedereu, 't welck niet can geloven haer $\mathrm{B}$. intentie te wesen. Doch 't is goet sich te precautieneeren en daer op naerdere explicatie versoecken 't welck U.E. bidde te willen comuniceeren aen eenige Uwer Speciale Vrienden die van sodanige Saecken wel g'informeert sijn. - Mij dunckt oock (onder beter advis) dat men niet can gehouden sijn een placaet 't observeeren eer dat gepubliceert is, men can wel gehooraemen in 't toecomende maer niet voor 't gepasseerde; Dit placael is germaneert off ingestelt den 3 April 1677 en gepnbliceert den 23 ditto, ende men wil dat hij zal standt grijpen van den 31 Januarij 1671, 't welck een onmogelijehe saeche is; Ingevalle men was gewaerschouwt geweest van Sodanigen voornemen door de Heeren Staten van Hollandt soo soude meu sich naer advenant hebben connen reguleeren maer soude nu willen dat men ter executie stelden, hetgeene sij mogelijck selfs niet en hebben geweten. De geene die in Hollandt sijn gebleven hebben middelen gehadt om aldaer te winnen, 't welck anderen, die geretireert sijn niet hebben connen doen, alsoo niet hebben connen genieten de gelegentheden en benefitien van 't Landt.

Ick heb wel een jaer en meer te vooren te kennen gegeeven dat ick 't Antwerpen soude gaen wonen met mijn Huijsvrouwe om geruster te connen leven dat alsdoen ijedereen approbeerde en selfs verscheijde Heeren van de Magistraeten.

Versoecke hier op reflectie gelieft te nemen; en mij UE gevoelen daer over adviseeren sult mij besonderlijch verobligeeren.

Uit dit betoog kan men opmaken hoe reeds van oudsher de opvatting gold dat aanslag van uitwonenden in de sirpc/s belastingen zich behoort te bepalen tot voor zoover zij grondbezit of voortgezet gebruik van een huis of een gedeelte daarvan op het grondgebied van den belastingheffer hebben. Aan deze traditionneele rechtsopvatting blijft dus de Regeering in haar ontwerp getrouw, doch zij strekt $\mathrm{m}$. i. het begrip van "gebruik" of "medegebruik" al te ver vit.

Zie over het bedoelde Placcaat Gr. Place. B. IIl. bl. 1078: en Res. der Staten van Holland en West-Friesland van 3 April 1677. Het aangehaald request berust op het Amsterd. archief in eene verzameling papieren betreffende onderwerpen in besogne gesteld bij Heeren Gedeputeerden van Amsterdam ter Dagvaert in den Haag.

A. D. van Assendelift de Coningh.

Leiderdorp, Nov. 1896. 